\title{
Temellendirilmiş Kuramda Gerçeklik ve Görecelik Uzlaşması ${ }^{1}$
}

\author{
DOI: 10.26466/opus.566221
}

\author{
* \\ Ayşe Nur Pekasıl* - Zehra Erşahin** \\ * Yüksek Lisans Öğr. Ankara Yıldırım Beyazıt Üni., Sosyal Hizmet Böl. Ankara/ Türkiye \\ E-Posta: aysnr pksl 93@hotmail.com ORCID: 0000-0003-1864-0359 \\ ** Dr. Öğr. Üyesi, Ankara Sosyal Bilimler Üni., Uygulamalı Psik.A.B.D. Dalı Ankara/Türkiye \\ E-Posta: zehra.ersahin@asbu.edu.tr ORCID: $\quad$ 0000-0002-9349-8586
}

\section{Öz}

Bu çalışma Grounded theory Türkçeye çevrisinde yaygın kullanımıyla temellendirilmiş kuram veya gömülü teori, araştırma metodunun doğuşundan günümüze kullanım şeklinin evrimine dikkat çekerek diğer nitel metotlarla farkına vurgu yapmak ve bugünün araştırma dünyasında araştırmaların felsefi bir zemine yerleştirmek isteyen aday araştırmacılar için kaleme alınmıştır. Bilimsel çalışmalarda nitel ve nicel araştırma yaklaşımlarının üstünlüğüne ilişkin tartışmaların süregeldiğgi bir ortamda günümüz sosyal bilim araştırmalarında nitel yöntemlerden bilimsel zenginliği artırılmış düzeyde faydalanmak hedefi bu çalışmada önem kazanmaktadır. Nitekim temellendirilmiş yaklaşım; sosyal bilimler araştırmalarında gerçeklik ve göreceliğin uzlaşabileceği bir çerçeveyi sunmakla birlikte, çalışmanın ve verinin zenginliği ile eşdeğer bilgi yönetim süreçleri sağlama potansiyeline sahiptir. Bu çerçevede kaleme alınan bu çalışmada, temellendirilmiş kuram yönteminin felsefi ve epistemolojik zemini yer verilmiştir. Felsefi zemininde felsefi hermeneutik ve epistemolojik zemininde pragmatizm ele alinarak yöntemin bilimsel zenginliği artırılmıştır. Bununla birlikte, araştırmacıların faydalanabilecekleri literal temel metinler ve uygulama basamaklarn hem bilimsel bir titizlik hem de sanatsal bir yaratıcll kla takip edilmesine olanak sağlayacaktır.

Anahtar Kelimeler: Temellendirilmiş kuram, gömülü teori, pragmatizm, hermeneutik; gerçeklik, görecelik

\footnotetext{
${ }^{1}$ Bu makale ikinci yazarın danışmanlığında birinci yazarın "Kendine Zarar Verme Davranışında Bulunan Gençler Üzerine Bir Araştırma" isimli Ankara Yıldırım Beyazıt Üniversitesi Sağlık Bilimleri Enstitüsünde Yayınlanmamış Yüksek Lisans Tezi esas alınarak gelişstirilmiştir.
} 


\title{
Reconciling Realist and Relativistic Foundations of Grounded Theory Methodology: A Guide for Researchers
}

\begin{abstract}
Current work reviews the philosophical underpinnings of the Grounded Theory-or "Temellendirilmis Kuram" or "Gomulu Teori" as translated into Turkish, with an aim to identify the shift from its critical realist epistemology to a more relativistic stance; and its difference to other qualitative approaches in aiding researchers utilising the methodology. The debate over qualitative versus quantitative data is still raw, indicating the need for strengthening good quality qualitative research methods. Here, Grounded Theory has lot to offer in reconciling realist and relativist underpinnings of a scientific inquiry; with a potential of providing a wealth of tools to work on equally rich resources of data. To do so, the review goes into both epistemological and philosophical roots of the method, and discusses its links to hermeneutics in its philosophical contextand pragmatism in its epistemological context. Researchers are also offered with fundamental readings in aiding their field work and subsequent analysis processes with a precise but artistic approach.
\end{abstract}

Keywords: Grounded theory, pragmatism, hermeneutics, reality, relativity 


\section{Giriş}

Temellendirilmiş kuramın ortaya çıkışı, sosyoloji disiplininde nicel ve nitel araştırma yaklaşımları arasında birtakım tartışmaların meydana geldiği 1960'lı yıllara denk gelmektedir. Bu tartışmaların şekillendirdiği bir ortamda, sayısal ve istatistiksel yaklaşımlar aracılığıyla elde edilen nicel testlere ilişkin aşırı güven duyan eğilimlere karşılık olarak 1967 yılında sosyolog Barney G. Glaser ve Anselm L. Strauss tarafından temellendirilmiş kuram geliştirilmiştir (Ilgar, 2013). Sonrasında Glaser ve Strauss tarafından kaleme alınan "The Discovery of Grounded Theory: Strategies for Qualitive Research" kitabı yayınlanmıştır. İlk aşamada sosyoloji disiplini içerisinde gelişen temellendirilmiş kuram sonrasında sosyal bilimlerin birçok disiplininde nitel araştırma desenleri içerisinde benimsenip kullanılan bir metot olmuştur (Charmaz, 2015). 1967'den bu yana temellendirilmiş kuramın metodolojik yapısı değişmezken, yöntemin gelişmesiyle birlikte pratiğine bir takım detaylar eklenmiştir (Corbin ve Strauss, 1990).

Stern (1982) temellendirilmiş kuramı; modelleri ve süreçleri keşfetmeye aynı zamanda bir grup insanın sosyal etkileşimleri içerisinde kendi gerçekliklerini nasıl tanımladıklarını anlamaya olanak veren bir yöntem olarak tanımlamıştır. Gelişen seyrinde Strauss ve Corbin (1994) temellendirilmiş kuramı; sistematik olarak toplanıp beraberinde sitematik olarak analiz edilen verilere dayanarak sistem ya da davranışı açıklamak ve tanımlamak için geliştirilen bir yöntem olarak tanımlamışlardır. Flint (2005) ise, doğrudan verilerden teori, kavram ve öneriler keşfeden bir yöntem olarak tanımlamıştır (Flint'ten aktaran Çelik ve Ekşi, 2015). En genel tanımıyla temellendirilmiş kuram yaklaşımı; bir teori geliştirmek amacıyla insan etkileşimi içerisinde mevcut olan sosyal süreçlerle ilgili verileri sistematik toplama ve analiz yöntemidir (Charmaz, 2012; Cutcliffe, 2000).

$\mathrm{Bu}$ tanımlar çerçevesinde temellendirilmiş kuram araştırmasının; tümevarımsal süreçlerle elde edilmesi, kuramsal detaylandırmaya bağlı kalması ve çeşitli değerlendirme kriterleri açısından kendi alanı için yeterli olduğunu ortaya koyması gerekmektedir (Haig, 1995).

Temellendirilmiş kurama ilişkin üç ana yaklaşım bulunmaktadır. Strauss ve Corbin tarafından oluşturulan sistematik yaklaşım, Glaser ile 
anılan klasik yaklaşım ve üçüncüsü Charmaz tarafından son dönemlerde daha çok vurgu yapılan yapılandırmacı yaklaşımdır.

$\mathrm{Bu}$ yaklaşımlardan herhangi birini benimseyen temellendirilmiş kuramcılar birbirlerinden bir takım uygulamalarda açısında ayrılsalar da temellendirilmiş kuramı diğer nitel araştırma modellerinden ayıran yöntemin temel niteliklerine bağlı kalmışlardır.

Temellendirilmiş kuramcilar;

- Tekrarlanan süreç içinde verileri toplar ve analiz ederler.

- Süreç boyunca araştırmanın veri toplama şeklini değiştirebilirler.

- Yüzeyde görünür olarak bulunan temalardan ziyade teori için analiz yaparlar.

- Tema ve yapı yerine eylem ve süreçleri analiz ederler.

- Sistematik olarak uyguladıkları veri analizleri sonucunda tümevarımsal soyut analitik kategoriler geliştirirler.

- Araştırılan kategorilerde çeşitlilik ararlar.

- Belirli bir bilimsel konuyu kapsama amacı gütmeksizin oluşan kategoriler üzerine yoğunlaşırlar.

- Kuramsal örneklem ile meşgul olurlar.

- Çalışılan birimi tanımlamak yerine sosyal sahnede baskın olan süreçleri keşfetmeye çalışırlar.

- Var olan bir kuramı açıklamak yerine gelişmekte olan kuramı diğer kuramlarla ilişkilendirirler.

- Kavramsal çerçeveyi önceki çalışmalardan ziyade verinin kendisi oluşturur (Charmaz, 2015; Stern, 1980).

Corbin ve Strauss (1990); nitel araştırmaların, bilimsel araştırmaların yaygın kanunlarına (anlamlılık, teori gözlem uyumu, tutarlılık, doğrulanabilirlik) tutunması gerektiğini savunmakla birlikte bilimsel perspektifin nitel araştırmanın gerçekliğine ve sosyal olguların karmaşıklığına uyması için yeniden tanımlanması gerektiğine vurgu yaparlar. Buradan yola çıkarak bu çalışmada, David L. Rennie tarafından ortaya konulan ve temellendirilmiş kuram sürecinde gerçeklik- göreceliği uzlaştıracak şekilde tasarlanan yeni mantık felsefi hermeneutik ve pragmatizimle ele alınmıştır. 


\section{Temellendirilmiş Kuramda Felsefi Hermeneutik}

Hermeneutik Yunancada "açıklamayla ilgili", "açıklayıcı" anlamına gelen hermeneutikos sözcüğünden gelmektedir (Bauman, 2017). Açı olmayanı açık hale getirmek ya da anlamın yorumlanması olarak ifade edilen hermeneutiğin tarihsel arka planı geniştir. Hermeneutiğin ilk izlerini Grek mitolojisinde bulmak mümkündür. Tanrı Hermes, tanrıların mesajlarını insanların anlayacağ 1 şekilde yorumlayarak insanların dünyasına aktaran tanrıdır (Öztürk, 2009). Antik Çağ'da sofistler, hermeneutiği sözel olanın arkasında yatan anlamın dinleyiciler tarafından açığa çıkarılmasını sağlayan bir sanat olarak görmüşlerdir. Platon'un "İon Diyoloğu" eseride hermeneutiğe sanat olarak bakışın bir örneğidir (Aşkın ve Çelik, 2015). Hristiyanlığın başlangıç döneminde, dini metinlerin altında yatan daha derin hakikatlere ulaşmak amacıyla tercih edilen bir yöntem olmuştur. Sonraki dönemlerde Friedrich Ast, Christin Wolf, Schleiermacher, Dilthey ile hermeneutik üzerine çalışmalar devam etmiştir (Öztürk, 2009). Ancak hermeneutiğin tarihsel gelişim süreci bu çalışmanın konusunu aştığından, burada Dilthey'in bazı fikirlerine yer verilerek temellendirilmiş kurama katkılarına işaret edilecektir.

Felsefi hermeneutik yukarıda kısaca belirtilen geniş bir tarihsel bağlam içerisinde şekillenmiş olup süreç içerisinde üç farklı tanımı ortaya çıkmıştır.

- Metinleri anlama ve yorumlamanın genel öğretisi,

- İnsan davranışları ve eserlerinin anlaşılmasının genel öğretisi,

- İnsanın kendi ontolojik temellerini anlaması olarak tanımlanmıştır (Topakkaya, 2007).

Her üç tanım da muhtevasında bir "anlama" eğilimi barındırmaktadır. Zira Dilthey'in tin bilimleri üzerine yapmış olduğu çalışmaları anlama sürecini; bilgiyi kuramsal, yöntemsel ve mantıksal bir zemine oturtma çabalarının şekillendirdiği düşünülebilir.

Dilthey, yaşantı ve anlama kavramını birleştirerek bu birleşimi tinsel ve sosyal bilimlerin önemli bir özelliği olarak ifade eden ilk düşünürdür (Topakkaya, 2007). Dilthey, bilimleri araştırma nesnelerine göre doğaya yönelen ve tarihe yönelen olmak üzere ikiye ayırmıştır. Nesnesine göre yaptığı bu ayrımda doğaya yönelenlerin doğa bilimlerini tarihe yönelenler tin bilimlerini oluşturmaktadır. Doğa bilimlerinin bilginin üretilmesi 
sürecinde genel ve nedensel yasaları içeren açıklama yöntemini kullandığına (Gülenç, 2017); buna karşlık tekil insan varoluşunun büyük formlarının (dil, din, ekonomi, kültür, hukuk, siyaset, ahlak, sanat, felsefe gibi kültür öğeleri ve bunlarla meydana gelen insani yaşama formları) açıklamayla doğrudan ele alınabilecek alanlar olmadığına vurgu yapmıştır (Öztürk, 2009).

Dilthey'e göre yaşamın kendisi ve onun ayrılmaz bir parçası olan insan ancak ve ancak yaşamın içinden bir bakışla anlaşılabilir. Merkezde yer eden konu bir açıklama nesnesi değil bir anlama nesnesidir. Bu sebepten dolayı Dilthey "anlama kuramını" geliştirmiştir (Vanleene, 2017).

Dilthey anlamayı, psişik yaşamın duyusal olarak işlenebilecek işaretlerinden yola çıkarak bu psişik yaşamın bilgisine ulaşma süreci olarak tanımlamıştır. Bu durumda anlama "içsel deneyim ile sürekli değişim sürecini temel alan bir oluşum hali" kazanmaktadır (Bauman, 2017, s.48). İçsel deneyimin ve dişsal deneyimin sürekli değişim süreci yeniden kurmayı beraberinde getirmektedir. Bir başka deyişle, araştırmacı bu dışsal tekil işaretleri yeniden kurma yöntemiyle kendi varoluşunda içsel olanla birleştirerek anlamlandırmaktadır (Dilthey, 1900).

Burada anlama ve yeniden kurmayla ilgili iki sürece işaret etmek gerekmektedir. İlk olarak bireyler kendi deneyimlerini gerçekleştirecekleri yolların seçiminde söz sahibi olmakla birlikte bu deneyimlerin bireylerin ilgilerinden, değerlerinden ve inançlarından doğrudan etkilenmesi kaçınılmazdır. Dolayısıyla bireyin deneyimlerinin oluşması, bireyin kendisine verilen dışsal gerçekliğin içsel gerçeklik ile yeniden kurulmasıyla oluşan bir yorumlama yani anlamlandırma süreci olarak düşünülebilir. İkinci olarak; deneyimin anlamını yorumlama konusunda en iyi pozisyonda duran kişi bizzat deneyimi yaşayan kişi olmasına rağmen deneyimin deneyimleyen kişi açısından ifade edilmesi zor olabilmektedir. Dolayısıyla deneyimi yorumlamaya yardımcı olacak kişi deneyimin dışında kalan yabancı bir kişi olacaktır. Yabancı kişinin eylemi gerçekleştiren bireylerin psişik durumlarını anlaması önce onların davranışlarını, seslerini ve vücut hareketlerini kavrayarak; sonrasında ise bunları içselleştirerek mümkün olacaktır. Ancak yabancı kişi de her koşulda kendi değerlerinden, inancından ve deneyimlerinden bağımsız kalamayacak ve etkilenerek yorumlamayı gerçekleştirecektir. Yani ikinci 
süreçte de anlamanın yabancı kişinin içsel ve dışsal deneyiminin birlikteliğinden meydana geldiği görülmektedir.

Dolayısıyla anlama ortak paylaşılan ve insanın kendini başkalarıyla ve eşyayla sürekli etkileşim içerisinde bulunduğu bir dünya içerinde gerçekleşmektedir (Öztürk, 2009). Dilthey tarafından ortaya konulan bu duruş Descartes ile başlayan bağlamından yalıtılmış özne fikri yani ‘özne merkezli epistemolojiye' karşıt bir duruş sergilemektedir. Bu şekilde ifade edilen bir anlama eylemi, "öznesi ile nesnesi arasında ya da daha doğru bir ifade ile iletişimin başlangıcında ve sonunda duran iki özne arasında bir yakınlığın kurulması" ile başlamaktadır (Bauman, 2017, s.35).

Birey, kendiliğini ve deneyimlerini ancak yabancı bir kişi aracılığıyla yorumlamakta ve anlamlandırmaktadır. Bireyin kendiliğinin ve deneyimlerinin farkına varması kendi dışında olan her şeyi yeniden kurmasını gerekli kılarak bireyi yabancı kişilerle etkileşimde kalmaya mecbur kılmaktadir.

Bu açılımda temellendirilmiş kuram uygulamasında çıkan herhangi bir kuramın açıklamayla doğrudan ilgili olmayıp daha ziyade anlamayla ilgili olması nedeniyle metodun hermeneutik yaklaşımla ele alınması uygundur. Zira temellendirilmiş kuram analizi süreci kişinin kendi yorumladığı deneyimin yabancı kişi tarafından tekrar yorumlanmasını gerektirir. Temellendirilmiş kuramda "anlayış" analiz sürecinde kategoriler ve kategoriler arasındaki ilişkilerin kurulması ile elde edilir. Temellendirilmiş kuramcının hem araştırmacı olması hem de analist olması ve bunu eş zamanlı olarak yapması içsel ve dişsal deneyimin birleşmesine imkân tanır. Böylece temellendirilmiş kuram sürecinde yer alan sürekli karşılaştırmalı analiz (constant comperative analysis) tam da bu noktada içsel ve dişsal deneyime kulak vererek "iyi/ehil" yorum yapmaya olanak sağlamaktadır.

\section{Temellendirilmiş Kuramda Pragmatizm}

Pragmatizm, 19. yüzyılın sonunda Amerika merkezli olarak ortaya çıkmış ve sonrasında geniş bir coğrafyaya yayılmış bir düşünce akımı olarak tanınsada Peirce'e (1879) göre pragmatizm aslen düşünceleri açık ve seçik hale getirmede ve kavramların anlamlarını belirlemede yöntemdir. Peirce'in bu tanımlamasına karşın pragmatizm genelde yanlış anlaşılmış 
ve pragmatistler zaman zaman bu yanlış anlamanın önüne geçmeye çalışmışlardır. Bu amaçla Dewey kendi pragmatizmini "araçsalcılık"; Schiller "hümanizm" olarak ifade etmiştir (Türer, 2003). Her ne kadar kelimenin Türkçe karşıllğ 1 "yararcıllı" ya da "insanın kendi çıkarı için hareket etmesi" algısını oluşturacak şekilde ele alına gelmiş olsa da, tarihsel izleri sürüldügünde pragmatizmin anlama, gerçeğe, araştırmaya ve etiğe dair söyledikleri sosyal bilimlerde yeni perspektifler oluşturmuştur (Doğan, 2003).

Peirce'in $(1878,1879)$ pragmatizmi; bir yandan tecrübi bir yandan bilimsel niteliktedir. Bununla birlikte Peirce'in pragmatizminin modern felsefede baskın olan kartezyen kanaatlere tepki olarak ortaya çıktığı yani anti-kartezyen bir yaklaşım olduğu da unutulmamalıdır. Descartes şüpheyi bir veri olarak kabul etmiştir ve bireyin kendi varlığının bilincine mantık yoluyla ulaşabileceğini savunarak akıl ve beden ikiliğine dayanan bir felsefe ortaya koymuştur. Oysa pragmatizm insani özelliklerden ve perspektiflerden arınmış bilgi elde etme arzusu taşıyan bu düşünce geleneğine karşı olarak bireylerin kendilerini diğer insanlar aracılığıyla tanıyabileceğini, fikirlerin ancak diğer fikirler ile görünürlük kazanacağını ve kavramların diğer kavramlar ile daha açık ve anlamlı olabildiğini savunmuştur (Doğan, 2003; Ömer, 2002). Bu noktada önemli pragmatistlerden olan ve bireyin toplumdan bağımsız ele alınamayacağını yani toplumsallaşmadan bireyselleşemeyeceğine vurgu yapan George H. Mead'in (1934) bazı fikirlerine yer vermek pragmatizmin hayata dair etkileşimci ve bütüncül bakışını netleştirmesi açısından önem kazanmaktadır.

Mead (1934), birey ve toplumun ayrilmaz olduğunu vurgularken; kendisi için bir nesne olabilecek benliğin temelde sosyal bir yap1 olduğunu ve toplumsal deneyimlerle açığa çıkıp şekillendiğini savunur (s.140). Benlik, sosyal deneyimlerle ortaya çıktıktan sonra, kendi sosyal deneyimlerini kendine refakat edercesine sürdürüp sağlayabileceği münzevi bir hayat sürdürebilir; ancak aksi mümkün değildir. Bir başka deyişle birey, benliği toplumsal düzeyde inşa edildiğinde kendisini arkadaş edindiği ve onunla başkalarıyla iletişim kurduğu gibi konuşabildiği bir formu sürdürebilir. Bu süreç, bireyin kendine başkasına cevap verircesine iletişim kurması, başkalarıyla iletişimde ne söyleyeceğini tanıması, 
birinin ne söylediğinin ve devamında ne söyleyeceğini belirlemek adına ne söylediğinin farkındalığını kullanmak şeklinde nükseder.

$\mathrm{Bu}$ durumu ise bireyin içinde yaşadığ toplumu kişileştirmesi olarak tanımlamış ve bu tanımın düşüncenin oluşumuyla bağlantısını kurmuştur. Mead'e göre düşüncenin oluşum süreci ego ile kişileştirilmiş toplum arasında bireyin içinde kurulan diyalogla özdeştir. Birey kendisini kişileştirilmiş toplumun yerine koyup egoya sanki nesneymiş gibi bakabildiğinde düşünce yeteneğini kazanmaktadır. Bu noktada kişilik, ego ve kişileştirilmiş toplumun karşılıklı eylemleriyle oluşmaktadır (Atiker, 1997).

Peirce, Mead'den faydalandığ şekliyle bilim ve bilgiye bakışını inanç ve düşünce teorileri üzerinden ifade etmiştir. Peirce'ın çalışmaları onun bilime ne kadar bağlı olduğunu doğrudan göstermektedir. Ancak bu bağlılık Peirce'ın bilim otoritesini getirmiş olduğu eleştirilerin önünde bir engel olmamıştır. Peirce bilimlerin tecrübeye dayandığını ve mutlak kesinlik üretmediğini de vurgulamıştır (Türer, 2003).

Peirce düşünmenin asıl işlevinin inanç üretmek olduğunu savunmuş ve inancı insanı eyleme hazırlayan faaliyet olarak tanımlamıştır. Peirce inancın birey tarafından farkında olunduğuna, bireyde rahatsızlık halini dinginleştirdiğine ve bireyde bir alışkanlık (eylem kuralı) oluşturduğuna vurgu yaparak inanca operasyonel bir tanım geliştirmiştir (Peirce, 1878). $\mathrm{Bu}$ durumda pragmatizm yaklaşımında bireyin düşüncelerinin inanç oluşturmalarına ve inançların ise bireyleri eyleme geçirmesine araç olduğu düşünülebilir. Bu varsayım bireylerin düşüncelerinin gözlenebilir olgular olduğunu ima eder. Yani bireylerin davranışlarının nasıl olduğuna bakarak ne tür düşünceler içerisinde olduğu anlaşılabilmelidir (Doğan, 2003). Peirce'in inanç ve düşüncelerine ilişkin ifadelerinden yola çıkarak; insanın eylemesinden önceki süreçlerini şu şekilde betimlemek uygun olacaktır: Süreç bir yolculuk olarak düşünülürse bu yolculuğun başlangıç noktasını şüphe (eyleme teşvik eden ve tatmin olmayış durumu) oluşturmaktadır. Bitiş noktasını ise inanç (eyleme hazırlayan ve tatmin oluş durumu) oluşturmaktadır. Yolculuk sırasında kullanılan vasıtanın ise düşünme olarak isimlendirilmesi mümkündür. Betimlenerek ifade edilen bu süreci Peirce araştırma olarak isimlendirmiş ve sadece araştırma sayesinde gerçek şüpheden sağlam bir inanca geçişin mümkün olacağını savunmuştur. 
Burada inanç ve düşünce teorilerine kısaca değindikten sonra epistemolojik zeminde inancın sabitlenmesine ve inancın doğruluğu mevzusuna yer vermek gerekmektedir. Peirce inançların sabitlenmesinde tarihsel olarak etkili olmuş üç yöntemden bahseder ve bunlardan ziyade tatminkâr bir yol olan bilimsel yöntemin kullanımını savunur. Tarihsel olarak kullanılan ilk yöntem, insanların çevresindekilere karşı gözlerini kapatması olarak ifade edilebilen inat yöntemidir. Peirce bu yöntemin bir devekuşunun tehlike anında kafasını toprağa gömdüğünde etrafında herhangi bir tehlikenin olmadığına inanmasına benzetmiştir. Peirce bu yöntemin kimi zaman işe yarar olabileceğine değinir ancak Mead'in teorize ettiği şekliyle sosyal güdüye aykırı olduğunu savunur. Yani bu durumun sürekli değiş̧en ve karşılıklı etkileşim halinde olunan bir çevrede korunamayacağını savunur. Yaygın olan ikinci yöntem ise otorite yöntemidir. Bu yöntemde bireyin neye inanacağ bu yöntemin etkili olamayacağını çünkü hiçbir kurumun her alanda fikirleri düzenlemeye gücünün yetmeyeceğini vurgulayarak dillendirir. Peirce tarihsel olarak kullanılan üçüncü yöntemin a priori yöntemi olduğunu söyler. Bu yöntemin ortaya koymuş olduğu fikirler büyük ölçüde gözlemlenmiş olgular üzerine temellendirilmez ve dayandığı temel önermeler "akla uygun" olduğu kabul edildiği ölçüde benimsenirler. Peirce diğer yöntemlere göre bu yöntemin daha entelektüel ve saygıdeğer olduğunu savunur. Bununla birlikte uygulanabilecek daha iyi bir yöntem olmadığı sürece bu yöntemin izlenebileceğini vurgular. Ancak bireyler sahip oldukları herhangi bir inancin, olgularla ilgisi olmayan bir durum sonucunda belirlendiğini görmeleri halinde inançlarının yerini kuşku alacağını savunur. Bu yöntemlere karşı Peirce tatminkâr bir yöntem olan bilimsel yöntemi savunmuştur. Bilimsel yöntemin temel varsayımlarını; Peirce'in gerçeğe bakışı, doğruya bakışı ve gerçeğe ilişkin ilkeleri oluşturmaktadır (Peirce, 1877).

Peirce (1877) "doğru düşünce" ifadesi ile kastettiği şeyin herkes tarafından kabul edilme olasılığı olan fikir olduğunu savunur. Bunun yanı sıra James (1907) ise "doğru düşünceyi" yaşamımızdaki bir sorunu çözme noktasında başarılı olmuş fikir olarak tanımlar. Bu iki ifade incelendiğinde ne kadar birbirinden bağımsız gibi görünseler de Peirce herhangi bir anda öznel ya da yanlış bir kanaat olmayacak demediği gibi, James de gelecekte nesnel bir doğru hiçbir zaman olamaz iddiasında 
değildir (Doğan, 2003). Nitekim Peirce'in fikirlerinde doğruluk anlayışının gerçeklik anlayışı üzerinden temellendiği ve bu anlayışın kesinlikçilik (absolutism) ve şüphecilik (skepticism) bilgi kuramlarına alternatif bir yol olarak okumak mümkün olacaktır. Peirce bu gerçeklik anlayışını bazı temel ilkelere dayandırır, bunlar yanlışlanabilirlik tezi, bilginin sosyal sebeplerden kaynaklandığı tezi, objektif idealizm anlayışı ve pragmatik maksim olmak üzere dört madde ile ifade edilebilir. İlk ilke Peirce'in yanılmacı bir görüş benimsediği ve bilginin geçici olduğunu vurguladığı savını vurgular. İkinci ilke, ilk olarak sosyal zorlamanın gerçekliği oluşturması, ardından bilgi sürecinin zaman içerisinde kendini doğrulamaya yönelik hareket etmesi savını takip eder. Üçüncü ilke objektif idealizm, bilinenin ötesine yapılan her atfın yanlış olabileceğini ifade eder. Pragmatik maksim olarak isimlendirilen son ilke ise, her hangi bir kavramın, sözcügüun, önermenin ve işaretin anlamının onun varoluşa uygulandığında ortaya çıkabilecek kavranabilir sonuçlarıyla ilişkili olduğunu savunur (Türer, 2015). Pragmatik maksim yöntemine göre; anlamları bulanık olan kavramlar, anlamları açık olan kavramlarla işlem içerisinde basamak basamak yer değiştirilmekte ve bu işlem kavramın anlamında gerçek bir açıklık oluşana kadar devam etmektedir (Çelik, 2018).

Bunlarla birlikte, Peirce geleneksel çıkarım yöntemleri olan tümdengelim ve tümevarıma ek olarak abdüksiyonun farklı bir çıkarım şekli olduğunu savunmuştur. Peirce'e göre tümdengelim yöntemi ile ortaya çıkan anlam kendi bünyesinde hali hazırda mevcut olmasından dolayı totolojiktir ve bu haliyle yeni bilgi üretme sürecine katkı sağlamamaktadır. Bunun yerine yeni bilgi üretme sürecini tümevarım ve abdüksiyon arasındaki etkileşim olarak ifade etmiş, abdüksiyonları hipotezin hayali olarak kurgulanması olarak tanımlayarak bu yöntemin bilim için büyük bir umut olduğuna vurgu yapmıştır (Rennie, 2000). Sonuç olarak gerçeklik, belirsizlik içerisindeki bir devamlılığ ifade ederken; doğruluk, belirli önermelerin doğaya ayna tutmasından ziyade önermelerin başka önermelerle olan ilişkisinin anlamlı olmasıyla ilişkilendirilmiştir. Bu noktada insan bilgisinin doğruluğa ilişkin mutlak bir kesinliği söz konusu olmamaktadır. İnsan bilgisinin doğruluğu, deneyimlere dayalı sabitlenmiş inancı ve dinlenme halinde bulunan düşünceyi ifade etmektedir.

$\mathrm{Bu}$ ayrımda pragmatizmin temellendirilmiş kuram bağlamında yönteme katkılarını anlamak için genel varsayımlarını özetlemek önem 
kazanmaktadır. Pragmatizm epistemolojide hem pozitivizmi hem de metafizikçi tecrübeciliği reddetmektedir. Pragmatizm ve pozitivizmin dogmatik fikirlere karşı durmaları ve ilkeler yerine olgulara odaklanmaları üzere kesiştiği düşünülebilir ancak aralarında önemli farklılıklarda bulunmaktadır. Pozitivizmin doğrulanma ilkesi, sosyal bilimlerde yapılan araştırmaların değer yargılarından bağımsız olarak yapılması gerektiğini savunur. Oysaki pragmatizmde, değerler bireylerin davranışlarıyla bağlantılı olduklarından göz ardı edilmemelidir (Atiker, 1997). Bu noktada pozitivistler bilimlerin bilimsel metot ile açılayamadıkları her şeyi göz ardı etmeye çalışırken, Peirce ve takipçileri bilimsel metodu mümkün olduğunca genişletmeye çalışmışlardır (İnönü, 2008). Bununla birlikte pragmatistler Descartes ile ortaya atılan ve uzun bir süre savunulan içe bakışçllı̆̆ ve egoizmi reddetmiş, yöntemsel kuşkuculuğa karşı çıkmış; şüphenin genel olarak bütün inançlara uygulanamayacağını savunmuşlardır.

Dünyanın çoğulcu bir yapıda olduğunu, ilerlemenin mümkün olduğunu, düşüncelerimizin işlerliği konusunda yaşadıklarımıza bakarak görüş elde edebileceğimizi vurgulamışlardır (Doğan, 2003; Türer, 2015). Ayrıca bireylerin dünyada bir fark oluşturabileceğini; bir başka deyişle bireylerin her zaman kullanmamakla birlikte içerisinde bulunmuş oldukları koşullara cevap verme araçlarıyla kaderlerini kontrol etme gücüne sahip olduğunu vurgulamışlardır (Corbin ve Strauss, 1990). Bunlara ek olarak pragmatistler insanların olaylara ilişkin kendi gerçekliklerini nasıl tanımladıklarını ve bu tanımlamalara karşılık nasıl eylemde bulunduklarını ortaya koymaya çalışarak bireyin anlamın oluşturulması sürecinde aktif rol aldığını vurgular. George Herbert Mead'in "toplumsal yaşam deneyimi" ve "toplumun kişileştirilmesi" olarak ifade ettiği ve bireyin anlam oluşturma sürecindeki etken rolünü vurgulayan kavramlar temellendirilmiş kuramda da karşılık bulmaktadır. Temellendirilmiş kurama göre toplumun içerisinde varlığını devam ettiren birey her ne koşulda olursa olsun çevresinden etkilenmekte ve çevresini etkilemektedir. Dolayısıyla bireyler bu etkileşimli ortam içerisinde kendi gerçekliklerini inşa etmektedirler. Bu durum temellendirilmiş kuram yöntemi insan etkileşimlerinin ortaya konulduğu her türlü süreç ile yakından ilgilenmesini zorunlu kılmaktadır. Bu durumda pragmatistlerin sürekli vurguladıkları; kendimizi diğer insanlar aracılığı ile tanıyabileceğimiz, 
fikirlerin ancak diğer fikirler ile görünürlük kazanabileceği ve kavramların ancak diğer kavramlar ile açık ve seçik hale gelebileceği temellendirilmiş kuramın ilkeleri ile örtüşmektedir.

Pragmatizmin evren anlayışında; sabit, durağan, monist ya da düalist klasik töz anlayışlarının yer almadığını bunun yerine öznenin bağlamına göre varoluş kazanan tözlerin öne sürüldüğü görülmektedir (Çelik, 2018). $\mathrm{Bu}$ noktada temellendirilmiş kuram, olguların durağan olarak tasarlanmadığını ve olguların değişen koşullara tepki veren sürekli bir değişim içerisinde olduğunu; sadece ilgili koşulları ortaya çıkarmayı değil, aynı zamanda bireylerin değişen koşullara ve eylemlerin sonuçlarına nasıl tepki verdiğini belirlemeyi amaçlamaktadır (Corbin ve Strauss, 1990).

\section{Uygulamada Hermeneutik, Pragmatizm ve Temellendirilmiş Kuram}

Bahsi geçtiği şekliyle Peirce, Strauss ve Corbin, ve diğer teorisyenlerin çalışmaları çerçevesinde şekillenen bu yaklaşım bu bölümde David L. Rennie'nin (hermeneutik ve Pierce'in çıarım teorisi) fikirleriyle zenginleştirilerek araştırmacılara yol göstermesi amaçlanmıştır. Böylelikle yeni mantık temellendirilmiş teori içerisinde hermeneutiği Pierce'ın çıkarım teorisiyle birleştirip somutlaştırarak gerçeklik ve göreceliği uzlaştıracak şekilde tasarlanmıştır.

Rennie, Strauss'un yöntemine bağlı kalarak daha iyi bir doğrulama yöntemi elde etmeyi amaçlamıştır. Bu doğrulama yöntemine ise metodolojik hermeneutik adını vermiştir. Descartes tarafından ortaya atılan özne-nesne ikiliğine ve zihin-beden ayrımına eleştiride bulunarak Heiddegger'in insanların dünya ile simbiyotik bir ilişkide bulunduğu fikrini benimsemiştir. Özellikle insan bilimlerinin sürekli kendi kendini yorumlamak zorunda olması hermeneutik ile doğrudan ilişki kurmayı gerektirdiğini savunmuştur. Bu noktada hermeneutik ile Peirce'in çıkarım teorisini birleştirmiştir. Peirce tümdengelim ve tümevarıma ek olarak üçüncü bir çıkarım teorisi olan abdüksiyonu (abduction) ileri sürmüştür. Peirce tümdengelimin kendi bünyesinde teolojik bir sonucu üreterek zorunlu (apodictic) bir gerçeklik kanıtı ortaya koyma şekli olması sebebiyle yeni bilgi üretmeye olanak sağlamadığına vurgu yaparak yeni bilginin tümevarım ve abdüksiyon arasındaki etkileşimden meydana geldiğini ortaya koymuştur. Abdüksiyonu ise şu şekilde ifade etmiştir: Bir bilim 
adamının bir veri grubu ile çalışırken elde ettiği bulguyu açıklayamadığ1 varsayılırsa, bilim adamı bu durumda veriyi açıklayabileceği bir neden hayal eder. Bu hayal edilen neden ise bulguyu açılama noktasında bir kapasiteye sahip olduğunu gösterir. Dolayısıyla hayal edilen nedeni açıklamak için bilim adamının elinde halihazırda ilk bakışta göze çarpan bir zemin bulunmaktadır. Özetle Peirce'a göre bilimsel bir süreç abduction'a yol açan gerçeklerin toplanması olan tümevarımı içermektedir (Peirce'dan aktaran Rennie, 2000).

Peirce bu şekilde doğa bilimlerine mantık uygulamaya çalışmıştır. Bu uygulamada hayal gücüne yapmış olduğu atfın yorumlamaya kapı aralaması ve bilginin değişim içerisinde olduğunu dolayısıyla mutlak olmadığını vurgulaması hermeneutik ile bağ kurulmasına olanak vermiştir. Bu mantık uygulaması ise temellendirilmiş kuram sürecinde geçerli her hangi bir kategori (kategorileri kavramsallaştırmak için kullanılan prosedürlere bakılmadan) analiz ilerledikçe geçerliliğinin oluşması beklenen bir abdüksiyon (hipotez)'dur. Bu noktada süreç boyunca incelenecek metne verilen anlama bağlı kalarak kategoriler değiştirilebilir, çıkarılabilir ve ya bir başka kategori altında değerlendirilebilir (Rennie, 1998; Rennie, 2000). Kategorilerin oluşturulması süreci abdüksiyonların oluşmasını ve kategorilerin değişim süreci de abdüksiyonların sınanmasını göstererek tümevarımsal bir süreç içerisinde analizi ilerletmektedir. Bu süreçte metnin anlamına göre kategorilerin oluşturulması ve sınanması ise araştırmayı hermeneutik döngüye dâhil etmektedir.

Çalışmada temellendirilen teorik zemini sahada uygulamak niyetinde olan araştırmacı adayların izlemesi gereken ilkeler ve adımlar genel hatlarıyla çizilecek olursa;

- Nereden başlanacağı hakkında bir bilgi edinilerek sahaya çıkılmasi

- Yarı- yapılandırılmış sorular ile kuramsal çatının test edilmesi

- Kapsamlı bir teori geliştirmek yerine, kavramsal açıklamalar düzeyinde kalınarak var olan- ifşa gelen durumların açıklanması

- Teorik hassasiyetin ilk etapta verileri derinlemesine incelemek yerine yöntemin uygulanma adımlarında sinırlı tutulması

- Kavramsal açıklamalarda araştırmacının durduğu pozisyonun etkisini baştan kabul etmesi 
- Kavramsal açıklamaların güvenilirliğini yöntemin titizliği ile temin edilmesi

- Araştırmacının duruşunu netleştirmek adına etken edimlerle süreci ifadelendirme - örneğin veriler kavramsal açıklamalar ortaya koyuyor demek yerine, araştırmacı kavramsal açıklamalarını ortaya koymak için verileri yapılandırılmıştır ifadesinin tercih edilmesi

- Kodlamaların nasıl yapılacağının adım adım tanımlanması; kodların, kelimelere göre analiz verisi içeren mikro analizden türetilmesi

- Kodlamanın üç aşamada gerçekleştirilmesi: Açık kodlama (olayları tanımlama, adlandırma, kategorilere ayırma ve açıklama), Eksenel kodlama (kodları birbirine bağlama işlemi) ve Seçici kodlama (çekirdek bir kategori seçme ve diğer kategorileri ilişkilendirme) (Jones ve Alony, 2011).

Son olarak bu çalışmada yazarların temellendirilmiş teori yönteminin felsefi ve epistomolojik zemininde sirasiyla felsefi hermeneutik ve pragmatizmi ele almasının amac Rennie'nin de vurgulamış olduğu şekilde gerçeklik ve görecelik arasındaki boşluğu daha aza indirmek istemesidir. Böylece kullanılan yöntem, araştırmacının hem bilimsel bir titizlik hem de sanatsal bir yaratıcılıkla araştırmayı yürütmesine olanak sağlayacaktır. 


\title{
EXTENDED ABSTRACT
}

\section{Reconciling Realist and Relativistic Foundations of Grounded Theory Methodology: A Guide for Researchers}

\author{
Ayşe Nur Pekasıl - Zehra Erşahin \\ Ankara Yıldirım Beyazıt University-Ankara Social Science University of Ankara
}

Current work reviews the philosophical underpinnings of Grounded Theory Methodology (GTM), with an aim to identify the shift from its critical realist epistemology to a more relativistic stance in aiding researchers utilising the methodology. The debate over qualitative versus quantitative data is still young, indicating the need for strengthening good quality qualitative research methods. This is unfortunate for graduate students and early career researchers who are expected to find a rigiorous approach to their subject of interest, while conciling the current context of debates on methods and philosophical positions such as realism, relativism, positivism, constructivism, and so on. If a qualitiative approach is chosen the rationale for doing so calls for a strong justification of the choice, its link to the phenomena under interest, and prospective outcomes. Here, Grounded Theory has lot to offer in reconciling realist and relativist underpinnings of a scientific inquiry; with a potential of providing a wealth of tools to work on equally rich resources of data.

GTM is gounded on both onotological and epistemological foundations, through a step-by-step data collection and analysis procedure with the flexibility of discussing the outome and its alternatice explanations. Its strength do not come from its follow-up path however, that it combines appropriate use of data, existent knowledge, intuition and researchers own experience. To aid this process, Peirces's pragmatism proves an inspirational add-in to the equation with a open-mind reflexive process of empirical research in discovering new knowledge. With an aim to underpin the foundations rof such an addon, the review goes into both epistemological and philosophical roots of the method, and its link to hermeneutics and pragmatism with an aim to aid the field work and subsequent analysis processes with a precise but artistic approach. This stance therefore suggests that texts, and their producers, should be studied within the social context in which they were formed, which 
characterizes an internal realistic experience: in other words a pragmatic realism that is internal to the conceptual meaning systems of human beings, opposing metaphysical realism in which there is a single-objective way of describing how the world is. This of course, contrasts the use of scientific methodology in textual understanding, where a common sense can be applied to the meaning moving beyond the author's own interpretation of their experience.

The modern world took quite a hectic outlook in which several contrasting images of phenomena/knowledge/theory exist, and in constant change. Concerning this chaos, grounded inquiry can prove a rigorous approach into the aspects of social world, by generating conceptual frameworks that provide new coherent and consistent understandings of the hectic common-sense knowledge to interested audiences of those communities. With this in mind, current review also considers the existential conflict on what validity means in between the qualitative and quantitative research paradigms. While the concept of validity in the quantitative world is measurable and reflect a sense of objective reality; those researchers who come from hermeneutic roots argue that there is no fixed external reality, that knowledge is constructed within groups (and larger groups such as ",society") and cannot be independent of people"s understanding of that group, since consciousness itself is embedded at the group level. In accordance with Heidegger there is a hermeneutic circle in between the text and context where meaning is created on the basis of "beinge and "relatingee.

Even though this stance poses a subjective viewpoint on creating and interpreting the meaning, the conventional methodological attitude in social science allows exploratory activities. With an aim to minimise the subjectivity bias and error, this stance should lead researchers taking extra activities and procedures during the data collection and analysis stages as suggested at the end of the review (i.e. validity and credibility checks). Taking these points into account, current piece will support reseachers in producing knowledge, from a world that the researcher comes from, or willing to live with; rather than judging the knowledge within the framework of a cause and effect paradigms.

\section{Kaynakça / References}

Aşkın, Z., ve Çellik, H. (2015). Hermeneutiğin ontolojik temellendirilişi: Heidegger ve Gadamer. Beytulhikme: An International Journal of Philosophy, 5(2), 2-32 
Atiker, E. (1997). Amerikan pragmatizmi ve güncel yaşam dünyası. İstanbul Üniversitesi Sosyoloji Dergisi, 3(4), 29-36.

Bauman, Z. (2017). Hermenötik ve sosyal bilimler. (H. Oruç, Çev.) İstanbul: Ayrıntı Yayınları.

Charmaz, K. (2012). The power and potential of grounded theory. Medical Sociology Online, 6(3), 2-15.

Corbin, J. M., ve Strauss, A. (1990). Grounded theory research: Procedures, canons, and evaluative criteria. Qualitative sociology, 13(1), 3-21.

Cutcliffe, J. R. (2005). Adapt or adopt: Developing and transgressing the methodological boundaries of grounded theory. Journal of Advanced Nursing, 51(4), 421-428.

Cutcliffe, J. R. (2000). Methodological issues in grounded theory. Journal of Advanced Nursing, 31(6), 1476-1484.

Charmaz, K. (2015). Gömülü (Grounded) Teori Yapılandırması (Cilt 2. Baskı). (R. Hoş, Çev.) Ankara: Seçkin Yayıncılık.

Çelik, H., ve Ekşi , H. (2015). Gömülü Teori. İstanbul: EDAM .

Doğan, N. (2003). Pragmatizmin felsefi temelleri. Erciyes Üniversitesi İktisadi ve İdari Bilimler Fakültesi Dergisi, 20(1), 83-93.

Dilthey, W. (2011). Hermeneutik ve tin bilimleri. (D. Özlem, Çev.) İstanbul: Notos Kitap Yayınevi.

Gülenç, K. (2017). Wilhelm Dithey'de hermeneutik yaklaşım ve açmazları. Cogito(89),129-145.

Haig, B. D. (1995). Grounded theory as scientific method. Philosophy of Education, 28(1), 1-11.

Ilgar, M. Z., ve Ilgar, S. C. (2013). Nitel bir araştırma deseni olarak gömülü teori (Temellendirilmiş Kuram). http://www.izu.edu.tr-/Assets/Content/File/Enstitu_Sekreterligi/2013_Guz_Donemi_M_Zeki_ilgar_ve_Semra_Cosgun_ilgar.pdf Erişim Tarihi: 14.04.2019,

İnönü N. (2008). Charles Sanders Peirce'ün pragmatizmi. İstanbul Üniversitesi Felsefe Arkivi Dergisi, 33, 31-41.

James, W. (1907). Pragmatism: A new name for some old ways of thinking. New York, NY, US: Longmans, Green and Co.

Jones, M. ve Alony, I. (2011). Guiding the use of Grounded Theory in Doctoral studies - An example from the Australian film industry. International Journal of Doctoral Studies, 6 (N/A), 95-114.

Mead, G. H. (1934). Mind, Self, and Society from the Standpoint of a Social Behaviorist. Chicago: University of Chicago Press. 
Ömer, F. (2002). Yeni pragmatizm, hermeneutik ve postmodernizm. Uludağ Üniversitesi Felsefe Topluluğu Dergisi(1), 120-133.

Öztürk, E. (2009). Hermeneutiğin tarihsel dönüşümü. Journal of World of Turks/Zeitschrift für die Welt der Türken, 1(2), 145-175.

Peirce, C. S. (1878). How to make our ideas clear. Popular Science Monthly (12), 286-302.

Peirce, C. S. (1877). The fixation of belief. Popular Science Monthly 12 (1), 1-15.

Peirce, C. S., James, W., ve Dewey, J. (2018). Pragmatizm pratik bir felsefe seçme yazıları. İstanbul: Doruk Yayımcılık.

Rennie, D. L. (1998). Grounded theory methodology: The pressing need for a coherent logic of justification. Theory \& Psychology, 8(1), 101-119.

Rennie, D. L. (2000). Grounded theory methodology as methodical hermeneutics: Reconciling realism and relativism. Theory \& Psychology, 10(4), 481-502.

Stern, P. N. (1980). Grounded theory methodology: Its uses and processes. Image, 12(1), 20-23.

Topakkaya, A. (2007). Felsefî hermeneutik. FLSF (Süleyman Demirel Üniversitesi Felsefe Bölümü) Dergi (4), 75-91.

Türer, C. (2003). Charles S. Peirce'ün Epistemolojisi. Bilimname: Düşünce Platformu, 2, 23- 52.

Türer, C. (2015). Charles Sanders Peirce. Doğu'dan Batı'ya Düşüncenin Serüveni Yirminci Yüzyıl Düşüncesi (s. 67- 97). İçinde İstanbul: İnsan Yayınları.

Vanleene, S., ve Acar S. M. (2017). Wilhelm Dilthey'da "Anlama" üzerine. Ankara Üniversitesi Dil ve Tarih-Coğrafya Fakültesi Dergisi, 52(1), 159- 171.

\section{Kaynakça Bilgisi / Citation Information}

Pekasıl, A. ve Erşahin, Z. (2019). Temellendirilmiş kuramda gerçeklik ve görecelik uzlaşması. OPUS-Uluslararası Toplum Araştırmaları Dergisi, 13(19), 2404-2422. DOI: 10.26466/opus.566221 